\title{
POTENSI KOMPOS TANDAN KOSONG KELAPA SAWIT UNTUK MEMASOK FOSFOR PADA PODSOLIK MERAH KUNING DAN SERAPANNYA OLEH BIBIT KELAPA SAWIT (Elaeis guineensis Jacq.)
}

\section{(POTENCY OF OIL PALM BUNCHES COMPOST FOR AVAILABLE P SUPPLY ON RED YELLOW PODSOLIC AND PHOSPHORUS UPTAKE BY PALM OIL (Elaeis guineensis Jacq.) SEEDLINGS)}

\section{Ulinnuha Difana Putri ${ }^{1)}$, Lelanti Peniwiratri ${ }^{\left.2)^{*}\right)}$ dan R. Agus Widodo ${ }^{2)}$}

${ }^{1)}$ Prodi Agroteknologi, Universitas Pembangunan Nasional Veteran Yogyakarta

2) Prodi Ilmu Tanah, Universitas Pembangunan Nasional Veteran Yogyakarta

${ }^{*}$ Corresponding author E-mail: lelanti@yahoo.com

\begin{abstract}
This research aims to determine role of TKKS compost in different doses by giving NPK for available $\mathrm{P}$ of Red Yellow Podsolik and growth of oil palm seedlings. The research was conducted at Instalasi Penelitian Tanah, Laladon, Bogor, Indonesia. The research was arranged in a Randomized Block Design consisting of 7 treatments with 6 replications. The treatments consist of No Treatment, NPK Standard, 3/4 NPK, 3/4 NPK + 1/2 TKKS, 3/4 NPK + 3/4 TKKS, 3/4 NPK +1 TKKS, $3 / 4$ NPK $+1 \frac{1}{2}$ TKKS. To know the effect of treatment on parameters, this research used analysis of variance (ANOVA). The mean differences between the treatments on result parameters were tested by Duncan Multiple Range Test (DMRT) 5\%. The results showed the application of TKKS fertilizers with different doses by giving NPK significantly increased P-available of Red Yellow Podzolic and P-uptake of oil palm seedlings. However, treatment of $3 / 4$ NPK $+1 / 2$ TKKS produced best results for P-available in Red Yellow Podsolic and P-uptake of oil palm seedlings.
\end{abstract}

Keywords: NPK, Oil Palm, Red Yellow Podzolic, Seed, TKKS Compost.

\begin{abstract}
ABSTRAK
Penelitian ini bertujuan untuk mengetahui pengaruh kompos TKKS berbeda takaran yang diberi NPK terhadap ketersediaan P Podsolik Merah Kuning dan serapannya oleh bibit kelapa sawit. Penelitian dilakukan di Instalasi Penelitian Tanah, Laladon, Bogor. Penelitian merupakan percobaan pot yang disusun dalam Rancangan Acak Kelompok (RAK) terdiri dari 7 perlakuan dengan 6 ulangan. Perlakuan tersebut terdiri dari Tanpa Perlakuan, NPK Standar, 3/4 NPK, 3/4 NPK $+1 / 2$ TKKS, 3/4 NPK+ 3/4 TKKS, 3/4 NPK+1 TKKS, 3/4 NPK+1 1/2 TKKS. Untuk mengetahui pengaruh perlakuan terhadap parameter penelitian dilakukan analisis sidik ragam (ANOVA). Beda rerata antar perlakuan terhadap parameter hasil dilakukan uji beda nyata Duncan Multiple Range Test (DMRT) 5\%. Hasil penelitian menunjukkan bahwa pemberian pupuk kompos TKKS berbeda takaran yang diberi NPK berpengaruh nyata meningkatkan P tersedia Podsolik Merah Kuning dan serapan $P$ oleh bibit kelapa sawit. Perlakuan $3 / 4$ NPK $+1 / 2$ TKKS memberikan hasil terbaik terhadap ketersediaan P Podsolik Merah Kuning dan serapannya oleh bibit kelapa sawit.
\end{abstract}

Kata kunci : Bibit Kelapa sawit, Fosfor, Podsolik Merah Kuning, TKKS 


\section{PENDAHULUAN}

Fosfor (P) merupakan salah satu unsur hara makro esensial yang dibutuhkan oleh tanaman dalam jumlah yang relatif banyak, karena unsur ini mempunyai peranan terhadap proses metabolisme maupun sebagai penyusun struktural molekul, sehingga kekurangan unsur P sangat berpengaruh terhadap pertumbuhan tanaman. Fosfor dalam tanah nisbi sulit untuk tersedia bagi tanaman, diduga fosfor merupakan unsur pembatas pertumbuhan tanaman yang menempati urutan ketiga setelah air dan nitrogen, khususnya di daerah tropik (Sanchez, 1992). Oleh karena itu, penambahan P dalam bentuk pupuk yang cukup bagi tanaman sangat diperlukan, terutama pada tanaman kelapa sawit yang membutuhkan $\mathrm{P}$ untuk menunjang pertumbuhan bibitnya.

Kelapa sawit (Elaeis guineensis Jacq.) merupakan komoditas perkebunan yang penting dalam perekonomian Indonesia karena menjadi komoditas andalan ekspor sebagai penghasil devisa negara dan dapat menciptakan lapangan kerja. Indonesia menjadi produsen utama minyak kelapa sawit atau crude palm oil (CPO) terbesar di dunia dengan luas perkebunan kelapa sawit pada tahun 2012 mencapai 9.27 juta ha dengan produksi CPO mencapai 25.6 juta ton.Pengembangan perkebunan kelapa sawit di Indonesia mengalami peningkatan yang sangat pesat. Dari tahun 2000 - 2008, rata rata peningkatan luas tanaman kelapa sawit 7,53\% dimana peningkatan tertinggi terjadi pada tahun 2008 yaitu 24\% (dari 5,68 menjadi 7,04 juta ha) (Kasno dan Nurjaya, 2011). Penyediaan bibit kelapa sawit untuk memenuhi peningkatan kebutuhan luas areal penanaman kelapa sawit tersebut diatas tentu tidak terlepas dari penggunaan bibit yang berkualitas yang didapatkan melalui penggunaan benih yang secara genetik unggul dan pemeliharaan yang baik, terutama pemupukan. Namun, sebagian besar perkebunan menggunakan bibit berkualitas rendah yang berasal dari brondolan lepas di kebun serta pengelolaan pupuk yang rendah. Hal tersebut disebabkan oleh kurangnya informasi dan pengetahuan mengenai pengelolaan pembibitan yang baik serta penggunaan pupuk yang tepat. Fosfor $(\mathrm{P})$ merupakan salah satu hara makro primer yang dibutuhkan untuk pertumbuhan optimum pada pembibitan kelapa sawit.

Podsolik Merah Kuning berpotensi sebagai media tumbuh kelapa sawit karena penyebarannya yang sangat luas namun masih belum banyak dimanfaatkan. Saat ini diperkirakan $60 \%$ dari luas areal perkebunan kelapa sawit di Indonesia terdapat pada tanah Podsolik Merah Kuning. Podsolik Merah Kuning merupakan tanah berpelapukan lanjut atau sudah tua, di Indonesia banyak ditemukan di daerah dengan bahan induk lempung (Hardjowigeno, 1993).Tanah ini memiliki masalah keasaman tanah, bahan organik rendah dan ketersediaan nutrisi makro primer terutama Fosforr yang rendah (Syahputra et al., 2015). Mulyani et al. (2010) dalam Syahputra et al. (2015 )menyatakan bahwa kapasitas tukar kation (KTK), kejenuhan basa (KB) dan C-organik rendah, kandungan aluminium (kejenuhan $\mathrm{Al}$ ) tinggi, kandungan besi dan mangan mendekati batas meracuni tanaman serta peka terhadap erosi. Rendahnya hara hara makro primer terutama fosfor menyebabkan perlu adanya penambahan hara fosfor yang dapat diperoleh dari pemupukan. Upaya mengurangi penggunaan pupuk anorganik yang berlebihan, dapat dilakukan dengan menggunakan kompos atau pupuk organik. Pemberian bahan organik dalam bentuk kompos dapat memperbaiki sifat fisik, kimia dan biologi tanah seperti meningkatkan kapasitas air, kapasitas tukar kation, porositas, $\mathrm{pH}$, serta merangsang pertumbuhan mikroorganisme di dalam tanah. Pupuk organik dapat mengurangi kebutuhan $25 \%$ dari penggunaan pupuk NPK pada tanaman pangan dan hortikultura (Adamy et al., 2011). 
Kompos Tandan Kelapa Sawit (TKKS) yang berasal dari Tandan kosong kelapa sawit merupakan limbah padat dalam jumlah besar dari pengolahan minyak sawit dan dekat areal perkebunan kelapa sawit. TKKS merupakan salah satu bahan organik yang mengandung hara makro Nitrogen $(\mathrm{N})$, Fosfor $(\mathrm{P})$, Kalium $(\mathrm{K})$ dan Magnesium (Mg) sehingga dapat mengurangi penggunaan pupuk anorganik NPK yang apabila diberikan secara terus menerus dapat merusak struktur tanah. TKKS sekaligus dapat memperbaiki sifat fisik, kimia dan biologi Podsolik Merah Kuning. Winarti dan Neneng (2013). Kompos TKKS bersifat homogen dan mengurangi risiko sebagai pembawa hama tanaman dan dapat diaplikasikan pada berbagai musim Winarti dan Neneng (2013). Selain mampu memperbaiki sifat fisik tanah, kompos TKKS diharapkan dapat meningkatkan efisiensi pemupukan sehingga penggunaan NPK untuk pembibitan utama kelapa sawit dapat dikurangi dan biaya pemupukan anorganik dapat ditekan. Penelitian ini bertujuan mengetahui pengaruh pemberian kompos TKKS berbeda takaran yang diberi N,P, dan K terhadap ketersediaan P Podsolik Merah Kuning dan serapannya oleh bibit kelapa sawit (Elaeis guineensis Jacq.).

\section{BAHAN DAN METODE}

Penelitian ini dilaksanakan pada Tanah Podsolik Merah Kuning di Instalasi Penelitian Tanah, Jl. Sindang Barang No. 62, Laladon, Bogor. Analisis dilakukan di laboratorium Kimia Tanah dan Kesuburan, Balai Penelitian Tanah, Jl. Tentara Pelajar No. 12 Cimanggu, Bogor, Jawa Barat. Tanah Podsolik Merah Kuning diambil di areal lahan Kentrong, Lebak, Banten. Tanah tersebut dipilih karena mampu mewakili jenis tanah yang digunakan pada perkebunan kelapa sawit di Indonesia yang diperkiran $60 \%$ luas areal perkebunan kelapa sawit terdapat pada tanah Podsolik Merah Kuning.

\begin{tabular}{|c|c|c|c|}
\hline No & Macam Analisis & $\begin{array}{c}\text { Hasil } \\
\text { Analisis }\end{array}$ & Harkat (*) \\
\hline 1 & $\begin{array}{l}\mathrm{P}_{2} \mathrm{O}_{5} \text { Potensial (eks.HCl } \\
25 \%, \mathrm{mg} / 100 \mathrm{~g})\end{array}$ & 13 & Sangat Rendah \\
\hline 2 & P-Tersedia (eks Bray, ppm) & 1 & Sangat Rendah \\
\hline 3 & $\begin{array}{l}\text { KPK }(\operatorname{cmol}(+) / \mathrm{kg}) \\
\text { Tekstur }(\%)\end{array}$ & 6.57 & Rendah \\
\hline 4 & Pasir & 14 & \\
\hline 4 & $\begin{array}{l}\text { Debu } \\
\text { Lempung }\end{array}$ & $\begin{array}{l}42 \\
44\end{array}$ & Lempung berdebu \\
\hline 5 & C - Organik (\%) & 2.34 & Sedang \\
\hline 6 & $\mathrm{pH} \mathrm{H} \mathrm{H}_{2} \mathrm{O}$ & 4.45 & Sangat Masam \\
\hline 7 & $\mathrm{pH} \mathrm{KCl}$ & 3.90 & Masam \\
\hline 8 & $\begin{array}{l}\mathrm{Al}(\mathrm{eks} . \mathrm{KCl} 1 \mathrm{M} \\
\mathrm{cmol}(+) / \mathrm{kg})\end{array}$ & 40.91 & Tinggi \\
\hline 9 & $\begin{array}{l}\mathrm{H}(\mathrm{eks} . \mathrm{KCl} 1 \mathrm{M} \\
\mathrm{cmol}(+) / \mathrm{kg})\end{array}$ & 0.00 & - \\
\hline
\end{tabular}

Keterangan: (*) Balittanah 
Pupuk organik yang digunakan adalah kompos tandan kosong kelapa sawit (TKKS) dalam bentuk remah dan siap untuk diaplikasikan. Pupuk kompos tandan kosong kelapa sawit (TKKS) tersebut berasal dari Medan.

Tabel 2. Komposisi pupuk kompos tandan kosong kelapa sawit (TKKS)

\begin{tabular}{|c|c|c|c|c|}
\hline No & Parameter Uji & Hasil Uji & Satuan & Metode \\
\hline 1 & $\mathrm{pH} \mathrm{H}_{2} \mathrm{O}$ & 6.1 & - & $\begin{array}{l}\text { Potensiometri/ } \\
\text { pH meter }\end{array}$ \\
\hline 2 & $\begin{array}{l}\text { Bahan organik : } \\
\text { C-Organik (\%) } \\
\text { N-Total }(\%) \\
\text { C/N }\end{array}$ & $\begin{array}{c}26,58 \\
26 \\
1,02\end{array}$ & $\begin{array}{l}\% \\
\% \\
-\end{array}$ & $\begin{array}{c}- \\
\text { Walkley \& Black } \\
\text { Destruksi Basah } \\
\text { - }\end{array}$ \\
\hline 3 & $\mathrm{P}_{2} \mathrm{O}_{5}-$ Total & 0,39 & $\%$ & $\begin{array}{c}\mathrm{HNO}_{3} / \\
\text { Spektrofotometri } \\
\mathrm{HNO}_{3} / \mathrm{F}-\mathrm{AAS}\end{array}$ \\
\hline
\end{tabular}

Penelitian disusun dalam Rancangan Acak Kelompok (RAK) terdiri dari 7 perlakuan, sebagai berikut:

1. $\mathrm{P} 0=$ Tanpa Perlakuan

2. $\mathrm{P} 1=\mathrm{NPK}$ Standar (Urea 1,30 $\mathrm{g}+\mathrm{SP}-361,70 \mathrm{~g}+\mathrm{KCl} 1,40 \mathrm{~g}+$ Kieserit 1

g)

3. $\mathrm{P} 2=3 / 4 \mathrm{NPK}$ (Urea 0,975 g + SP-36 1,275 g, KCl $1.05 \mathrm{~g}+$ Kieserit

4. $\mathrm{P} 3=3 / 4 \mathrm{NPK}+1 \frac{1}{2}$ TKKS (Urea 0,975 $\mathrm{g}+\mathrm{SP}-361,275 \mathrm{~g}+\mathrm{KCl} 1.05 \mathrm{~g}+$ Kieserit $1 \mathrm{~g}+0,5 \mathrm{~kg}$ TKKS

5. $\mathrm{P} 4=3 / 4 \mathrm{NPK}+3 / 4$ TKKS (Urea 0,975 $\mathrm{g}+\mathrm{SP}-361,275 \mathrm{~g}+\mathrm{KCl} 1.05 \mathrm{~g}+$ Kieserit $1 \mathrm{~g}+0,75 \mathrm{~kg}$ TKKS)

6. $\mathrm{P} 5=3 / 4 \mathrm{NPK}+1 \mathrm{TKKS}$ (Urea $0,975 \mathrm{~g}+\mathrm{SP}-361,275 \mathrm{~g}+\mathrm{KCl} 1.05 \mathrm{~g}+$ Kieserit $1 \mathrm{~g}+1 \mathrm{~kg}$ TKKS)

7. $\mathrm{P} 6=3 / 4 \mathrm{NPK}+1 \frac{1}{2}$ TKKS (Urea 0,975 $\mathrm{g}+\mathrm{SP}-361,275 \mathrm{~g}+\mathrm{KCl} 1.05 \mathrm{~g}+$ Kieserit $1 \mathrm{~g}+1,5 \mathrm{~kg}$ TKKS)

Masing-masing perlakuan diulang 6 kali sehingga dibutuhkan 42 polybag. Polybag yang digunakan berukuran $40 \mathrm{~cm}$ x $50 \mathrm{~cm}$. Kebutuhan tanah untuk setiap polybag ialah $20 \mathrm{~kg}$ sehingga dibutuhkan $840 \mathrm{~kg}$ untuk 42 polybag. Pupuk anorganik yang digunakan adalah pupuk NPK yang telah dikonversikan menjadi pupuk tunggal yang meliputi Urea, SP-36, KCl, dan Kieserit masing masing sebanyak 1,30; 1,70; 1,40 dan 1,00 g/ tanaman. Pupuk organik yang digunakan adalah kompos tandan kosong kelapa sawit (TKKS) dalam bentuk remah dan siap untuk diaplikasikan. Pupuk kompos tandan kosong kelapa sawit (TKKS) tersebut berasal dari Medan. Bibit kelapa sawit yang digunakan berasal dari persilangan varietas Dura dan Psifera Simalungun berumur 3 bulan, atau bibit kelapa sawit yang baru dipindah dari pembibitan awal (pre nursery) ke pembibitan utama (main nursery). Bibit kelapa sawit yang dibutuhkan untuk setiap polybag ialah 1 bibit sehingga dibutuhkan 42 bibit kelapa sawit. Pengambilan contoh tanah Podsolik Merah Kuning dilakukan pada kedalaman 0-20 cm dari permukaan tanah kemudian dimasukkan ke dalam karung dan diberi label. Selanjutnya contoh tanah tersebut di bawa ke rumah kaca. Tanah tersebut dikeringanginkan, kemudian ditumbuk secara manual atau menggunakan grinder, setelah itu tanah diayak dengan ayakan berukuran $2 \mathrm{~mm}$. Tanah yang digunakan sebagai media tanam untuk setiap ulangan dalam masing- masing perlakuan sebanyak $20 \mathrm{~kg}$ kering angin/ polybag. 
Penanaman dilakukan dengan membuat lubang di tengah polybag yang telah diisi media tanam, kemudian bibit kelapa sawit dari pre nursery dipindahkan ke polybag bersamaan dengan tanahnya. Setelah ditanam, kompos tandan kosong kelapa sawit (TKKS) dimasukkan polybag dengan takaran sesuai perlakuan yaitu $0 ; 0,5 ; 0,75 ; 1$ dan $1,5 \mathrm{~kg} /$ polybag. Pemeliharaan dilakukan mulai dari awal tanam hingga waktu panen. Dalam proses pemeliharaan tersebut dilakukan penyiraman, penyiangan gulma dan perlindungan dari hama dan penyakit. Tata letak perlakuan penelitian bibit kelapa sawit di main nursery dalam pot percobaan (polybag) disusun di lapangan dengan pola segitiga sama sisi dimana jarak antara sisi masing-masing $90 \mathrm{~cm}$, atau jarak antara pot (polybag) perlakuan $90 \times 90 \times 90 \mathrm{~cm}$.

Pupuk Urea, SP-36, KCl sebagai perlakuan pupuk standar diberikan selama 16 kali, dan pupuk Kieserit digunakan sebagai pupuk dasar. Pemberian kompos tandan kosong kelapa sawit diberikan satu kali ketika proses penanaman. Pemberian pupuk anorganik NPK pada minggu ke 2 sampai dengan minggu ke 6 diberikan 1 minggu sekali, dan setelah umur 8 - 24 minggu pupuk diberikan setiap 2 minggu sekali. Pemupukan anorganik NPK minggu ke 2 - 3 sesuai dosis perlakuan, pada minggu ke 4 5 takaran diditingkatkan 2 kali dari dosis perlakuan, minggu ke 6 - 8 takaran ditingkatkan 3 kali dari dosis perlakuan, minggu ke 10 - 20 takaran ditingkatkan 4 kali dari dosis perlakuan, minggu ke $22-24$ takaran ditingkatkan 6 kali dari dosis perlakuan. Pupuk tunggal diberikan dengan cara ditugal di samping tanaman dengan jarak $3 \mathrm{~cm}$ dari pangkal batang dengan kedalaman $\pm 5 \mathrm{~cm}$. Sedangkan kompos tandan kosong kelapa sawit diberikan dengan cara disebar dipermukaan tanah disekeliling tanaman dan sebagian dibenamkan.

\section{HASIL DAN PEMBAHASAN}

Hasil analisis tanah di lokasi penelitian (Tabel 1) menunjukan bahwa Podsolik Merah Kuning yang digunakan dalam penelitian ini merupakan tanah yang miskin unsur hara dan memiliki tingkat kesuburan tanah yang rendah, dari tabel 1 yang menunjukkan nilai $\mathrm{pH} \mathrm{H}_{2} \mathrm{O}$ tanah yang tergolong sangat masam $(<4,5), \mathrm{pH} \mathrm{KCl}$ tergolong masam $(2,5-4,0)$ kadar hara $\mathrm{P}$ - potensial dengan kriteria sangat rendah (15-20 mg/100g), KPK tanah tergolong rendah $\left(5-16 \mathrm{cmol}^{(+)} / \mathrm{kg}\right.$ tanah), memiliki kadar C- organik sedang ( $2-3 \%$ ), dan kadar Al-dd yang tinggi (31- 60 mg/100g). Kemasaman tanah dengan nilai $\mathrm{pH}$ berkisar $<4,5$ tersebut dapat disebabkan oleh beberapa faktor, antara lain bahan induk tanah, iklim, bahan organik dan pencucian basa - basa. Podsolik Merah Kuning merupakan tanah yang berpelapukan lanjut dan banyak ditemukan pada daerah yang memiliki curah hujan cukup tinggi sehingga menyebabkan tingkat pencucian hara yang tinggi terutama basa - basa. Hilangnya basa - basa pada tanah tersebut menjadi penyebab utama kemasaman tanah. Kondisi ini menunjukkan bahwa Podsolik Merah Kuning berkendala kesuburan kimianya terutama rendahnya hara $\mathrm{P}$, karenanya perlu dilakukan upaya perbaikan kesuburan tanahnya. Hal ini sesuai dengan yang dikemukakan Damanik et al. dalam Syahputra et al. (2015) bahwa meningkatnya kemasaman tanah dapat disebabkan oleh beberapa hal diantaranya pencucian kation-kation yang digantikan oleh $\mathrm{H}^{+}$dan $\mathrm{Al}^{3+}$. Dari hasil analisis didapatkan kadar $\mathrm{Al}$ yang tergolong tinggi. Nilai $\mathrm{pH}$ tanah berhubungan dengan kadar aluminium dalam tanah, bahwa semakin meningkat nilai $\mathrm{pH}$ tanah akan diikuti oleh penurunan kadar Al di dalam tanah, sebaliknya dengan 
menurunnya $\mathrm{pH}$ tanah maka akan diikuti oleh meningkatnya kadar Al di dalam tanah.

Ketersediaan hara P Podsolik Merah Kuning tergolong sangat rendah hingga sedang. Hal tersebut dapat dipengaruhi oleh pH tanah Podsolik Merah Kuning yang sangat masam, pencucian, dan jumlah bahan organik tanah sebagai sumber unsur hara. Selain mempengaruhi ketersediaan hara, bahan organik juga mempengaruhi Kapasitas pertukaran kation (KPK). Hasil analisis (tabel 1) menunjukkan KPK Podsolik Merah Kuning tergolong rendah. Rendahnya KPK tanah dipengaruhi oleh kurangnya kadar bahan organik, jenis lempung, dan $\mathrm{pH}$ tanah Podsolik Merah Kuning yang sangat masam. Hal tersebut dikarenakan bahan organik yang telah terdekomposisi menghasilkan humus dalam tanah yang merupakan sumber muatan negatif tanah. Atmojo (2003) menjelaskan bahwa muatan koloid humus bersifat berubah-ubah tergantung dari nilai $\mathrm{pH}$ larutan tanah. Dalam suasana sangat masam ( $\mathrm{pH}$ rendah), hidrogen akan terikat kuat pada gugus aktifnya yang menyebabkan gugus aktif berubah menjadi bermuatan positif $\left(-\mathrm{COOH}^{2+}\right.$ dan $\left.-\mathrm{OH}^{2+}\right)$, sehingga koloid - koloid yang bermuatan negatif menjadi rendah, akibatnya KPK turun. Berdasarkan hasil analisis tanah sebelum perlakun kadar hara P- potensial dan $\mathrm{P}-$ tersedia Podsolik Merah Kuning tergolong sangat rendah. Podsolik Merah Kuning erat kaitannya dengan ketersediaan hara $\mathrm{P}$ yang rendah dalam tanah. Podsolik Merah Kuning merupakan tanah tua atau berpelapukan lanjut yang mengalami pencucian basa-basa secara intensif berdasarkan nilai mobilitasnya. Nilai mobilitas $\mathrm{Al}$ dan $\mathrm{Fe}$ yang paling kecil sehingga $\mathrm{Al}$ dan Fe tertinggal dan lebih dominan di dalam tanah. Al dan Fe oksida dapat mengikat $\mathrm{P}$ sehingga ketersedian $\mathrm{P}$ rendah di dalam tanah. Kadar bahan organik tanah juga mempengaruhi jumlah hara $\mathrm{P}$ yang ada dalam tanah. Bahan organik dapat membantu pelepasan jerapan hara $\mathrm{P}$ oleh $\mathrm{Al}$ dan Fe. Hal tersebut didukung oleh pernyataan dari Atmojo (2003) bahwa pengaruh bahan organik terhadap ketersediaan $\mathrm{P}$ dapat secara langsung melaui proses mineralisasi atau secara tidak langsung dengan membantu pelepasan $\mathrm{P}$ yang terjerap oleh $\mathrm{Al}$ dan Fe. Pada umumnya Podsolik Merah Kuning memiliki kejenuhan basa rendah, namun dari tabel 2 dapat diketahui bahwa kejenuhan basa dari Podsolik Merah Kuning sebelum perlakuan tergolong sedang. Hal ini tidak lepas hubungannya dengan nilai tukar kation Podsolik Merah Kuning dan KPK tanah, karena kejenuhan basa merupakan hasil bagi dari basa - basa yang dapat ditukarkan dan KPK tanah. Besarnya nilai kejenuhan basa dipengaruhi oleh nilai tukar kation dalam tanah dengan status rendah - sampai sedang dan KPK tanah yang rendah.

Status ketersedian hara fosfor Podsolik Merah Kuning karena adanya pengaruh pemberian kompos tandan kosong kelapa sawit (TKKS) berbeda takaran yang diberi NPK disajikan pada tabel 3. Dari tabel 3 dapat diketahui bahwa Peemberian kompos tandan kosong kelapa sawit (TKKS) nyata meningkatkan $\mathrm{C}$ organik Podsolik Merah Kuning. Kadar C organic semakin meningkat seiring dengan meningkatnya takaran TKKS. Pemberian 3/4 NPK + 1 TKKS (P5) dan 3/4 NPK + 1 $1 / 2$ TKKS (P6) memberikan kadar $C$ organik paling tinggi yaitu sebesar $1,90 \%$. Hal ini dapat terjadi karena pada perlakuan P5 dan P6 merupakan perlakuan dengan takaran kompos TKKS tertinggi apabila dibandingkan semua perlakuan. Kompos TKKS merupakan salah satu bahan organik yang mengandung kadar C- organik, sehingga dengan semakin tinggi pemberian kompos TKKS akan meningkatkan kadar C- organik Podsolik Merah Kuning. Hal ini sesuai dengan pernyataan dari Utami dan Handayani (2003), menjelaskan bahwa dengan pemberian bahan organik 
dapat meningkatkan kandungan $\mathrm{C}$ - organik tanah dan juga dengan peningkatan $\mathrm{C}$ organik tanah juga dapat mempengaruhi sifat tanah menjadi lebih baik secara fisik, kimia dan biologi.

Tabel 3. Pengaruh pemberian kompos tandan kosong kelapa sawit (TKKS) Terhadap Kadar C organik dan P tersedia

\begin{tabular}{|c|c|c|c|}
\hline \multirow{2}{*}{ No } & \multirow{2}{*}{ Perlakuan } & \multicolumn{2}{|c|}{ Kadar hara setelah perlakuan } \\
\hline & & $\mathrm{C}-$ Organik $(\%)$ & $\mathbf{P}$ - Tersedia (ppm) \\
\hline 1 & P0 Tanpa perlakuan & $1,54 \mathbf{a}$ & $13,06 \mathbf{a}$ \\
\hline 2 & P1 NPK Standar & $1,65 \mathbf{b}$ & $61,10 \mathbf{a b}$ \\
\hline 3 & P2 3/4 NPK & $1,71 \mathbf{b c}$ & $57,82 \mathbf{a b}$ \\
\hline 4 & P3 $3 / 4 \mathrm{NPK}+1 / 2$ TKKS & 1,80 bcd & $92,65 \mathbf{b}$ \\
\hline 5 & P4 3/4 NPK+3/4 TKKS & $1,86 \mathbf{c d}$ & $80,14 \mathbf{b}$ \\
\hline 6 & P5 3/4 NPK+1 TKKS & $1,90 \mathbf{d}$ & $156,87 \mathbf{c}$ \\
\hline 7 & P6 3/4 NPK+ 1 1/2 TKKS & $1,90 \mathrm{~d}$ & $122,44 \mathbf{b c}$ \\
\hline
\end{tabular}

Keterangan: Rerata yang diikuti huruf yang sama pada kolom yang sama menunjukkan tidak ada beda nyata berdasarkan Uji Jarak Berganda Duncan pada taraf 5\%.

Tingginya kadar C-organik secara berturut - turut pada perlakuan P3 hingga P6 menunjukkan bahwa peningkatan kadar $\mathrm{C}$ organik tanah berbanding lurus dengan jumlah penambahan takaran kompos TKKS yang diberikan. Perlakuan P3 memberikan hasil terbaik dalam meningkatkan kadar $\mathrm{C}$ - organik tanah. Hal ini dikarenakan dengan takaran 3/4 NPK + 1/2 TKKS (P3) mampu memberikan hasil yang tidak berbeda nyata dengan hasil dari takaran diatasnya. Perlakuan dengan hasil kadar C - organik terendah terdapat pada P0 (tanpa perlakuan). Hal tersebut dapat terjadi dikarenakan pada perlakuan P0 tidak ada penambahan pupuk organik, sehingga $\mathrm{C}$ - organik hanya bersumber dari kadar $\mathrm{C}$ - organik tanah sebelum perlakuan.

Pemberian pupuk kompos tandan kosong kelapa sawit (TKKS) berbeda takaran yang diberi NPK berpengaruh nyata dalam meningkatkan kadar P - tersedia Podsolik Merah Kuning kadar $\mathrm{P}$ - tersedia tanah pada semua perlakuan menunjukkan kenaikan apabila dibandingkan dengan $\mathrm{P}$ - tersedia tanah sebelum perlakuan yang hanya sebesar $1 \mathrm{ppm}$. Dari tabel 3 menunjukkan bahwa perlakuan P3 hingga P6 menunjukkan hasil kadar P - tersedia lebih tinggi apabila dibandingkan dengan perlakuan $\mathrm{P} 0, \mathrm{P} 1$ dan $\mathrm{P} 2$. Hal ini menunjukkan bahwa meningkatnya $\mathrm{P}$ - tersedia tanah secara nyata seiring dengan peningkatan pemberian hingga takaran 1 TKKS/ bibit. Namun, pemberian takaran TKKS diatasnya justru menurunkan kadar $\mathrm{P}$ - tersedia tanah. Peningkatan $\mathrm{P}$ - tersedia tanah sebagian dapat berasal dari pembebasan P- jerapan karena asam - asam organik dari proses dekomposisi TKKS mampu memblokir unsur Al pada Podsolik Merah Kuning dan sebagian lagi berasal dari masukan pupuk fosfat dari pupuk NPK yang mengalami pelarutan. Hal ini sesuai dengan penelitian Wibowo et al. (2017) bahwa pemberian kompos TKKS dan pupuk majemuk mampu meningkatkan $\mathrm{P}$ - tersedia pada pembibitan utama di tanah Podsolik Merah Kuning. Perlakuan P5 (3/4 NPK + 1 TKKS) menunjukkan hasil rataan tertinggi sebesar $156,87 \mathrm{ppm}$, namun perlakuan $3 / 4 \mathrm{NPK}+1 / 2$ TKKS (P3) lebih efisien dan ekonomis karena memberikan hasil yang tidak berbeda nyata 
dengan takaran diatasnya P6 (3/4 NPK + 1 1/2 TKKS) dan menujukkan hasil berbeda nyata dengan perlakuan $\mathrm{P} 0$ hingga $\mathrm{P} 4$.. Kadar hara $\mathrm{P}$ - tersedia terendah terdapat pada perlakuan P0 (tanpa perlakuan), yaitu sebesar 13,06ppm. Hal tersebut dikarenakan pada perlakuan P0 tidak ada penambahan pupuk NPK dan kompos TKKS, sehingga $\mathrm{P}$ - tersedia di dalam tanah lebih rendah karena unsur $\mathrm{P}$ pada Podsolik Merah Kuning banyak yang terjerap Al dan tidak ada masukan dari pupuk fosfat. Serapan hara menjadi salah satu indikator respon tanah terhadap pemupukan. Tanggapan serapan hara $\mathrm{P}$ terhadap pemberian kompos tandan kosong kelapa sawit (TKKS) berbeda takaran yang diberi NPK dapat dilihat dari parameter pertumbuhan tanaman dan serapan hara P bibit tanaman sawit yang diamati pada umur 6 bulan (tabel 4).

Tabel 4. Pengaruh pemberian kompos tandan kosong kelapa sawit (TKKS) yang diberi NPK P-tersedia, berat kering, kadar $\mathrm{P}$ jaringgan dan serapan $\mathrm{P}$

\begin{tabular}{ccccc}
\hline No & Perlakuan & $\begin{array}{c}\text { Berat } \\
\text { kering }(\mathbf{g})\end{array}$ & $\begin{array}{c}\text { Kadar-P } \\
(\boldsymbol{\%})\end{array}$ & $\begin{array}{c}\text { Serapan P } \\
(\mathbf{g} / \operatorname{tanaman})\end{array}$ \\
\hline 1 & P0 Tanpa perlakuan & $60,50 \mathrm{a}$ & $0,11 \mathrm{a}$ & $0,06 \mathrm{a}$ \\
2 & P1 NPK Standar & $216,38 \mathrm{~b}$ & $0,19 \mathrm{~b}$ & $0,42 \mathrm{~b}$ \\
3 & P2 3/4 NPK & $228,13 \mathrm{bc}$ & $0,14 \mathrm{a}$ & $0,33 \mathrm{bc}$ \\
4 & P3 3/4 NPK+1/2 TKKS & $293,93 \mathrm{~d}$ & $0,19 \mathrm{~b}$ & $0,56 \mathrm{~d}$ \\
5 & P4 3/4 NPK+3/4 TKKS & $266,50 \mathrm{~cd}$ & $0,18 \mathrm{~b}$ & $0,46 \mathrm{~cd}$ \\
6 & P5 3/4 NPK+1 TKKS & $233,43 \mathrm{bc}$ & $0,18 \mathrm{~b}$ & $0,43 \mathrm{bc}$ \\
7 & P6 3/4 NPK+1 1/2 TKKS & $266,92 \mathrm{~cd}$ & $0,19 \mathrm{~b}$ & $0,51 \mathrm{~cd}$ \\
\hline
\end{tabular}

Keterangan: Rerata yang diikuti huruf yang sama pada kolom yang sama menunjukkan tidak ada beda nyata berdasarkan Uji Jarak Berganda Duncan pada taraf 5\%.

Berat kering merupakan ukuran pertumbuhan dan perkembangan tanaman, dan berat kering juga mencerminkan hasil dari akumulasi senyawa organik yang berhasil disintesis oleh tanaman ke organ-organ lainya sehingga berat kering juga ikut meningkat seiring dengan perkembangan organ-organ tanaman tersebut. Berdasarkan tabel 4 menunjukkan bahwa pemberian pupuk kompos tandan kosong kelapa sawit (TKKS) berbeda takaran yang diberi NPK berpengaruh nyata dalam meningkatkan dan berat kering bagian atas tanaman apabila dibandingkan dengan tanpa perlakuan. Dari nilai rataan berat kering bagian atas tanaman (tabel 4) menunjukkan bahwa perlakuan P3 (3/4 NPK + 1/2 TKKS) menghasilkan berat kering bagian atas tanaman tertinggi sebesar 293,93 gram, apabila dibandingkan dengan semua perlakuan. Hal tersebut menunjukan bahwa pemberian $3 / 4$ NPK dan $1 / 2$ TKKS merupakan perlakuan terbaik dalam meningkatkan berat kering tanaman karena pemberian bahan organik berupa kompos TKKS dan NPK mampu membantu ketersediaan hara di dalam tanah dan memacu pertumbuhan tanaman dengan memberikan lingkungan tumbuh yang baik, sehingga dapat meningkatkan berat kering tanaman. Sedangkan, berat kering terendah terdapat pada tanpa perlakuan sebesar 60,50 gram. Hal tersebut karena pada tanpa perlakuan tidak ada penambahan pupuk NPK maupun kompos TKKS sehingga pertumbuhan kelapa sawit tidak optimal. Pemberian $3 / 4$ NPK dan kompos TKKS berbeda takaran menghasilkan berat kering lebih tinggi apabila dibandingkan dengan tanpa perlakuan, NPK Standar dan 3/4 NPK. Hal tersebut menunjukkan bahwa pemberian 
pupuk NPK dan kompos TKKS mampu menyediakan unsur hara yang dibutuhkan oleh bibit kelapa sawit dan bahan organik yang terdapat pada kompos TKKS dapat memperbaiki sifat fisik, kimia dan biologi tanah sehingga dapat mengoptimalkan pertumbuhan bibit kelapa sawit.

Pemberian pupuk kompos tandan kosong kelapa sawit (TKKS) berbeda takaran yang diberi NPK berpengaruh nyata dalam meningkatkan kadar $\mathrm{P}$ dan serapan $\mathrm{P}$ bibit kelapa sawit. Peningkatan ini akibat membaiknya sistem perakaran tanaman yang dibuktikan dengan peningkatan berat kering tanaman seiring dengan peningkatan pupuk NPK dan kompos TKKS yang diberikan. Peningkatan berat kering ini disebabkan oleh meningkatnya $\mathrm{P}$ tersedia tanah (tabel 3). Berdasarkan nilai rataan kadar hara $\mathrm{P}$ dan serapan $\mathrm{P}$ bibit kelapa sawit (tabel 4) menunjukkan bahwa perlakuan P3 memberikan hasil terbaik dalam meningkatkan kadar P dalam jaringan tanaman. Hal tersebut menunjukkan pemberian takaran $3 / 4$ NPK $+1 / 2$ TKKS mampu memberikan hasil yang tidak berbeda nyata dengan takaran diatasnya. Perlakuan P3 juga menunjukkan hasil kadar hara P tertinggi sebesar 0,19\%. Hal ini terbukti dengan paling tingginya serapan hara $\mathrm{P}$ sebesar $0.56 \mathrm{~g} /$ tanaman (tabel 4 ) oleh bibit kelapa sawit. Selain itu, apabila dibandingkan dengan perlakuan lainnya perlakuan P3 merupakan perlakuan dengan takaran TKKS terendah hanya $1 / 2 \mathrm{~kg}$ per bibit apabila digunakan dalam kondisi dilapangan akan lebih efisien dan ekonomis.

\section{KESIMPULAN}

Pemberian pupuk kompos TKKS berbeda takaran yang diberi NPK berpengaruh nyata meningkatkan P tersedia tanah Podsolik Merah Kuning dan serapan P oleh bibit kelapa sawit. Perlakuan $3 / 4 \quad$ NPK $+1 / 2$ TKKS memberikan hasil terbaik terhadap ketersediaan P Podsolik Merah Kuning dan serapannya oleh bibit kelapa sawit.

\section{DAFTAR PUSTAKA}

Adamy, I., Husnain dan Rosmimik. 2011. "Pengaruh Pupuk Organik dari Berbagai Sumber Bahan Baku terhadap Pertumbuhan Jagung (Zea mays L.)”. Jurnal Litbang Pertanian Balai Penelitian Tanah.

Atmojo, S. 2003. "Peranan Bahan Organik terhadap Kesuburan Tanah dan Upaya Pengelolaannya”. Pengukuhan Guru Besar. Surakarta: Fakultas Pertanian Universitas Sebelas Maret.

Balittanah. 2009. "Petunjuk Teknis Edisi 2 Analisis Kimia Tanah, Tanaman, Air, dan Pupuk". Balai Penelitian Tanah. Bogor.

Darmawijaya, M. I. 1997. "Klasifikasi Tanah". Gadjah Mada University Press. Yogyakarta.

Epstein, E. 1997. “The Science of Composting”. United State of America: Technomic Publishing Company, inc.

Fairhurst T.H and Mutert E. 1999. "Interpretation and Management of Oil Palm Leaf Analysis Data. Better Corps International. Vol. 13 No. 1.

Hardjowigeno, S. 1993. "Klasifikasi Tanah Dan Pedogenesis". Akamedika Pressindo. Jakarta.

Kasno A. dan Nurjaya. 2011. "Pengaruh Pupuk Kieserit terhadap Pertumbuhan Kelapa 
Sawit dan Produktivitas Tanah".Jurnal Littri 17 (4) : 133- 139.

Nasution, H.H. Hanum,C. Dan Lahay, R.R. 2014. "Pertumbuhan Bibit Kelapa Sawit (Elaeis guinensis Jacq) pada Berbagai Perbandingan Media Tanam Sludge dan Tandan Kosong Kelapa Sawit (TKKS) di Pree Nursery". Jurnal Online Agroekoteknologi. Vol. 2, No. 4 : 1419-1425

PPKS. 2003. "Potensi dan Peluang Kelapa Investasi Industri Kelapa Sawit di Indonesia". PPKS. Medan.

Rosa, Rahayu N. 2012. "Pengelolaan Pembibitan Tanaman Kelapa Sawit (Elaeis guineensis Jacq.) di Kebun Bangun Bandar PT. Socfindo Medan, Sumatera Utara". Skripsi. Gelar Sarjana Pertanian, Fakultas Pertanian, Institut Pertanian Bogor.

Sari, V.I., Sudradjat, dan Sugiyanta. 2015. "Peran Pupuk Organik dalam Meningkatkan Efektifitas pupuk NPK pada Bibit Kelapa Sawit di Pembibitan Utama". J. Agron. Indonnesia 43 (2) : $153-160$

Sanchez, P .A. 1992. Properties and Management of Soils in The Tropics. John Wiley

Sembiring, J.V., Nelvia dan Yulia A.E. 2015. "Pertumbuhan Bibit Kelapa Sawit (Elaeis guineensis Jacq.) Di pembibitan utama pada Medium Sub Soil Ultisol yang diberi Asam Humat dan Kompos Tandan Kosong Kelapa Sawit”. Jurnal Agroteknologi, Vol. 6 No. 1: 25-32.

Utami, S. N. H. dan S. Handayani. 2003. "Sifat Kimia Entisol pada Pertanian Organik". Jurnal Ilmu Pertanian. 10: 63-69.

Wibowo, B.S., Hanum H., dan Fauzi. 2017. "Aplikasi Kompos TKKS dan Berbagai Dosis Pupuk Majemuk untuk meningkatkan Hara N, P, dan K serta Pertumbuhan Bibit Kelapa Sawit (Elaeis guineensis Jacq.) pada Pembibitan Utama di Tanah Ultisol”. Jurnal Agroekoteknologi FP USU. Vol. 5 No. 3 (68) : $500-507$.

Winarti, S., dan Neneng, L. 2013. "Pengaruh Pemberian Limbah Kelapa Sawit terhadap Sifat Fisik, Kimia dan Biologi Tanah pada Lahan Kritis Eks Penambangan Emas". Jurnal Agripeat. Vol. 14 No. 2 : 53 - 58.

Yunindanova, M. B. 2009. "Tingkat Kematangan Kompos Tandan Kosong Kelapa Sawit Dan Penggunaan Berbagai Jenis Mulsa Terdapat Pertumbuhan Dan Produksi Tanaman Tomat (Llycopersicon Esculentum Mill.) dan Cabai (Capsicum Annuum I.)". Skripsi. Program Studi Agronomi, Fakultas Pertanian Institut Pertanian Bogor.

Zulhida, R. dan Rahmadi, W. 2013. "Ekstrak Tunas Bambu (Rebung) dan Kompos Meningkatkan Pertumbuhan Bibit Kelapa Sawit (Elaeis quineensis Jacq) di Main Nursery". Agrium. Volume 18 No. 1. 